\title{
Complete genome sequence of Planctomyces limnophilus type strain (Mü 290')
}

\author{
Kurt LaButti ${ }^{1}$, Johannes Sikorski ${ }^{2}$, Susanne Schneider ${ }^{2}$, Matt Nolan ${ }^{1}$, Susan Lucas ${ }^{1}$, Tijana \\ Glavina Del Rio", Hope Tice ${ }^{1}$, Jan-Fang Cheng ${ }^{1}$, Lynne Goodwin ${ }^{1,3}$, Sam Pitluck ${ }^{1}$, \\ Konstantinos Liolios ${ }^{1}$, Natalia Ivanova ${ }^{1}$, Konstantinos Mavromatis' ${ }^{1}$, Natalia Mikhailova ${ }^{1}$, \\ Amrita Pati ${ }^{1}$, Amy Chen ${ }^{4}$, Krishna Palaniappan ${ }^{4}$, Miriam Land ${ }^{1,5}$, Loren Hauser ${ }^{1,5}$, Yun-Juan \\ Chang $^{1,5}$, Cynthia D. Jeffries ${ }^{1,5}$, Brian J. Tindall2 ${ }^{2}$, Manfred Rohde ${ }^{6}$, Markus Göker ${ }^{2}$, Tanja \\ Woyke $^{1}$, James Bristow ${ }^{1}$, Jonathan A. Eisen ${ }^{1,7}$, Victor Markowitz ${ }^{4}$, Philip Hugenholtz ${ }^{1}$, Nikos \\ C. Kyrpides ${ }^{1}$, Hans-Peter Klenk ${ }^{2}$, and Alla Lapidus ${ }^{1 *}$ \\ ${ }^{1}$ DOE Joint Genome Institute, Walnut Creek, California, USA \\ ${ }^{2}$ DSMZ - German Collection of Microorganisms and Cell Cultures GmbH, Braunschweig, \\ Germany \\ ${ }^{3}$ Los Alamos National Laboratory, Bioscience Division, Los Alamos, New Mexico, USA \\ ${ }^{4}$ Biological Data Management and Technology Center, Lawrence Berkeley National \\ Laboratory, Berkeley, California, USA \\ ${ }^{5}$ Oak Ridge National Laboratory, Oak Ridge, Tennessee, USA \\ ${ }^{6} \mathrm{HZI}$ - Helmholtz Centre for Infection Research, Braunschweig, Germany \\ ${ }^{7}$ University of California Davis Genome Center, Davis, California, USA \\ *Corresponding author: Alla Lapidus
}

Keywords: stalk, multicellular rosettes, low salt tolerance, Gram-negative, Planctomycetales, Planctomycetes, GEBA

Planctomyces limnophilus Hirsch and Müller 1986 belongs to the order Planctomycetales, which differs from other bacterial taxa by several distinctive features such as internal cell compartmentalization, multiplication by forming buds directly from the spherical, ovoid or pear-shaped mother cell and a cell wall which is stabilized by a proteinaceous layer rather than a peptidoglycan layer. Besides Pirellula staleyi, this is the second completed genome sequence of the family Planctomycetaceae. P. limnophilus is of interest because it differs from Pirellula by the presence of a stalk and its structure of fibril bundles, its cell shape and size, the formation of multicellular rosettes, low salt tolerance and red pigmented colonies. The 5,460,085 bp long genome with its 4,304 protein-coding and 66 RNA genes is a part of the Genomic Encyclopedia of Bacteria and Archaea project.

\section{Introduction}

Strain Mü 290T (= DSM $3776=$ ATCC 43296) is the type strain of Planctomyces limnophilus [1]. Currently, there are six species placed in the genus Planctomyces [2], the type species of which is $P$. bekefii [3-5]. The type species was initially described as a fungus under the International Code of Botanical Nomenclature [3,6]. The species $P$. guttaeformis and P. stranskae were also initially described as fungi, with their names being revived under the Bacteriological Code in 1984 [7]. The genus name derives from the Greek words 'planktos', wandering, floating, and 'mukês' meaning 'fungus' to indicate a floating fungus [3], reflecting their initial descriptions as members of the fungi. The species epithet derives from the Greek words 'limnos', lake, and 'philos', friend, loving, to indicate lake-loving [1]. Strain Mü 290T together with another strain (strain $279=$ DSM 1115) have been isolated from the freshwater lake Plußsee in Holstein, Germany [1]. Other strains of P. limnophilus have been isolated from Schrevenpark, Lake Mondsee, a 'cattle manure' (all near Kiel, Germany), and leakage water from a (industrial) compost heap (probably also in Germany) and were 
originally stored at the IFAM collection (Institut für Allgemeine Mikrobiologie, University of Kiel, Germany) [8].

The rpoN gene from $P$. limnophilus has been used in complementation studies in order to demonstrate the range of phylogenetic groups within the domain Bacteria that are known to contain the alternative sigma factor $\sigma^{54}$ [9]. P. limnophilus strain Mü 290 strate the widespread presence of the dnaK (HSP70) multigene family in members of the orders Planctomycetales and Verrucomicrobiales [10]. Quite early, in 1996, a physical map of the genome of strain Mü 290 2 had been obtained [11]. P. limnophilus strain Mü $290^{\mathrm{T}}$ was also utilized in a comparative analysis of ribonuclease P RNA of the Planctomycetes [12]. Here we present a summary classification and a set of features for P. limnophilus Mü 290', together with the description of the complete genomic sequencing and annotation.

\section{Classification and features}

This organism has a distinct cell cycle, with sessile mother cells forming stalks that attach to surfaces or to other stalks and motile daughter cells that bud from the mother cell. Mother cells are spherical to ovoid with stalks composed of twisted fibrils [1]. The diameter of the mother cell is 1.1 to 1.5 $\mu \mathrm{m}$. Multiplication occurs by budding on the distal cell pole, yielding daughter cells which are monotrichously and polarly flagellated [1]. The carbon sources D-glucose, D-galactose, maltose, cellobiose, $\mathrm{N}$-acetyl glucosamine are utilized $(0.1 \% \mathrm{w} / \mathrm{v})$
(Table 1), but not glucuronic acid, D-fructose, Dribose, mannitol, starch, dextrin, inulin, salicin, pyruvate, citrate, $\alpha$-oxoglutarate, succinate, fumarate, malate, formamide, methylamine $\cdot \mathrm{HCl}$ $(0.136 \%)$, formate $(0.136 \%)$, urea $(0.09 \%)$, methane $(0.5 \%)$, methanol $(0.4 \%)$, ethanol $(0.4 \%)$, lactate, acetate, propionate, tartrate, glutarate, caproate, phtalate, glycerol $(0.186 \%)$, L-arginine, L-aspartate, DL-alanine, L-glutamate, L-glycine, Lhistidine, L-leucine, DL-phenylalanine, L-proline, and L-serine [1]. There is no aerobic acid formation from D-glucose, saccharose, D-fructose, maltose, D-galactose and mannitol, nor is there anaerobic acid formation from $\mathbf{D}$-fructose or mannitol. However, there is anaerobic acid formation from D-glucose, saccharose, maltose or galactose [1]. Anaerobic gas formation on Hugh-Leifson medium was not reported. $\left(\mathrm{NH}_{4}\right)_{2} \mathrm{SO}_{4}$ was utilized as a nitrogen source, but not $\mathrm{NaNO}_{2}(0.2-0.7 \%), \mathrm{NaNO}_{3}$ $(0.2-0.85 \%)$, methylamine $\cdot \mathrm{HCl}(0.675 \%)$ or urea $(0.46 \%)$ [1]. Strain Mü $290^{\mathrm{T}}$ does not require vitamin supplements. It is reported to perform dissimilatory nitrate reduction, gelatin liquefaction, $\mathrm{H}_{2} \mathrm{~S}$ formation and is tolerant to $30 \mathrm{vol} \%$ CO [1]. However, strain Mü 290 ${ }^{\mathrm{T}}$ is negative for decarboxylation of lysine or arginine, deamination of phenylalanine or lysine, oligocarbophilic growth, urease, nitrification, assimilatory nitrate reduction, anaerobic gas formation with nitrate, formation of acetoin (up to $27 \mathrm{~d}$ ) or indole, growth in or changes of litmus milk, tolerance of $50 \mathrm{vol} \% \mathrm{CO}$, and extracellular DNase [1].

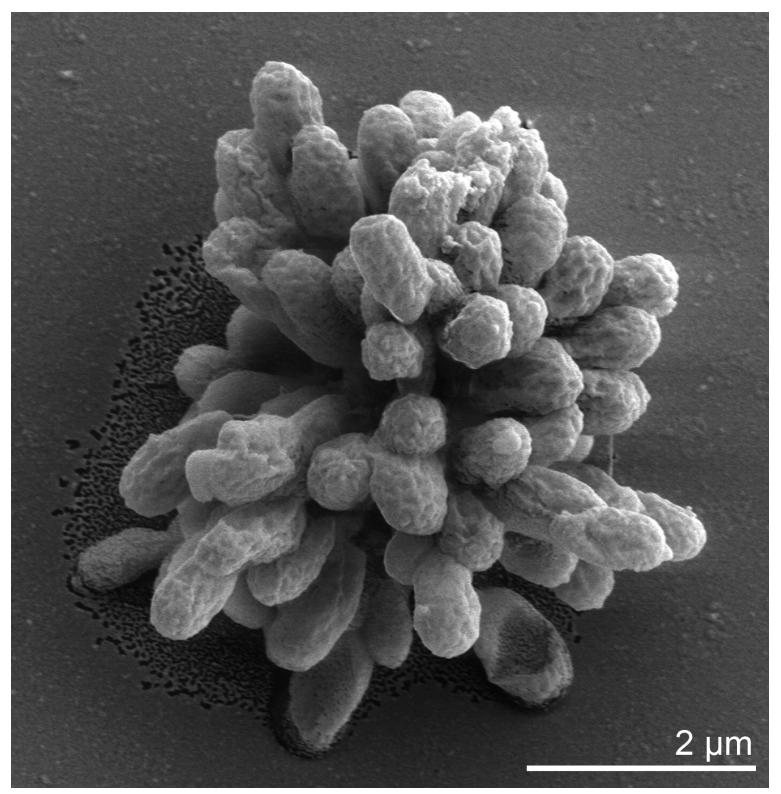

Figure 1. Scanning electron micrograph of $P$. limnophilus Mü $290^{\top}$ 
As a member of the order Planctomycetales, P. limnophilus strain Mü $290^{\mathrm{T}}$ is characterized by several distinctive morphological features such as rigid stalk fibers and the formation of multicellular rosettes (Figure 1) [1]. Further studies on another Planctomyces species, P. maris [21], revealed internal cell compartmentalization into the nucleoid, paryphoplasm, and a large ovoid central region [22]. The 16S rRNA gene sequence similarity values among isolates of the currently described species of this genus are sufficiently divergent to consider a re-examination of their taxonomy, e.g. the sequences of the two other type strains in the genus, P. maris [21] and P. brasiliensis [23] each share only $84.9 \%$ sequence identity with strain Mü $290^{\mathrm{T}}$ [the other three species in this genus are currently without an available type strain], whereas the other type strains from the family Planctomycetaceae share 78.8 to $82.8 \%$ sequence identity with strain Mü 290 ${ }^{\mathrm{T}}$ [24]. This view is indirectly supported by the establishment of the genus Schlesneria, which is placed within the radiation of the genus Planctomyces [25] with up to $88.2 \%$ sequence identity with strain Mü 290 . Any taxonomic re-arrangements are linked to the absence of suitable biochemical/physiological, gene sequence and chemotaxonomic data for the type species of the genus and two additional species. Uncultured clone sequences similar to the $16 \mathrm{~S}$ rRNA gene sequence from P. limnophilus were obtained from earthworm gut (98\%, FJ542967) [26], however, metagenomic surveys do not surpass $83 \%$ sequence similarity (status June 2010).

Figure 2 shows the phylogenetic neighborhood of P. limnophilus Mü $290^{\mathrm{T}}$ in a $16 \mathrm{~S}$ rRNA based tree. The sequences of the two identical 16S rRNA gene copies differ by one nucleotide from the previously published 16S rRNA sequence (X62911) generated from IFAM 1008, which contains one ambiguous base call.

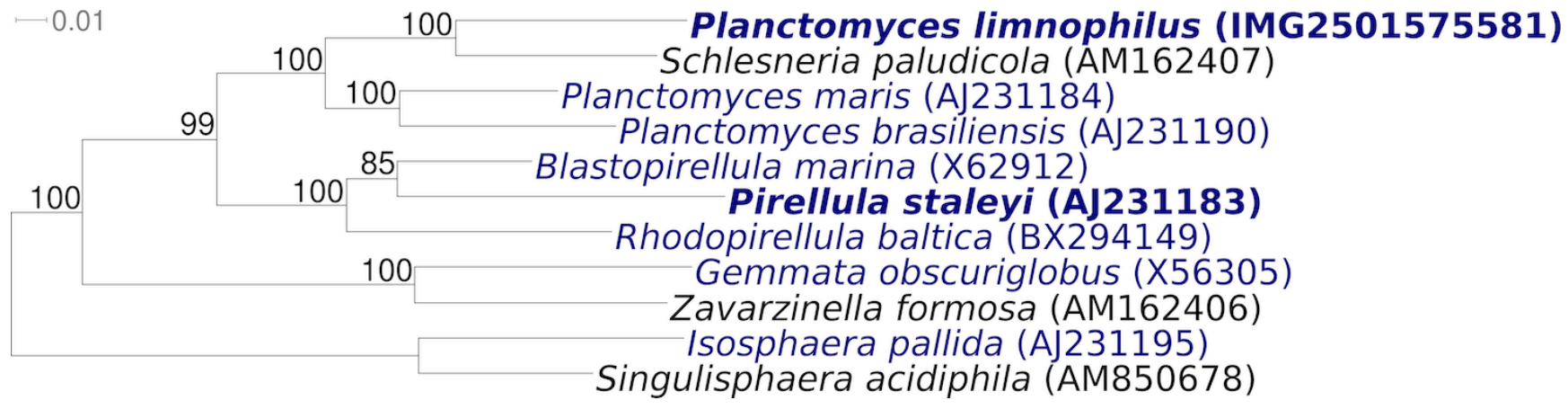

Figure 2. Phylogenetic tree highlighting the position of $P$. limnophilus Mü $290^{\top}$ relative to the type strains of the other species within the genus and to the type strains of the other genera within the family Planctomycetaceae. The tree was inferred from 1,336 aligned characters $[27,28]$ of the $16 \mathrm{~S}$ rRNA gene sequence under the maximum likelihood criterion [29] and rooted in accordance with the current taxonomy [30]. The branches are scaled in terms of the expected number of substitutions per site. Numbers above branches are support values from 1,000 bootstrap replicates [31] if larger than $60 \%$. Lineages with type strain genome sequencing projects registered in GOLD [32] are shown in blue, published genomes in bold, e.g. the recently published GEBA genome of Pirellula staleyi [33]. 16S rRNA gene sequences are not available for strains of the species $P$. bekefii, $P$. guttaeformis or $P$. stranskae, all of which are typified by descriptions and were initially described as fungi $[1,7]$. The name $P$. gracilis was also initially described as a fungus, but the name has not been validly published under the Bacteriological Code. Starr et al. [34] considered this organism not be to a planctomycete.

\section{Chemotaxonomy}

The genus Planctomyces lacks muramic acid and diaminopimelic acid, as was determined for $P$. $m a-$ ris [35]. However, a large amount of aspartic acid was found in whole cell hydrolysates [35]. Instead of containing peptidoglycan, the $10 \%$ SDS resistant cell envelope consisted almost entirely of protein which is rich in proline and cysteine and is stabilized to a high degree by disulfide bonds [36].
Comparable data are not available for P. limnophilus. The fatty acids in the polar lipids of strain Mü $290^{\mathrm{T}}$ are $\mathrm{C}_{16: 0}(46.6 \%), \mathrm{C}_{18: 1 \omega 9 \mathrm{c}}(20.6 \%), \mathrm{C}_{16: 1 \omega 7 \mathrm{c}}$ (18.4\%), C ${ }_{18: 1 \omega 7 \mathrm{c}}$ (5.5\%), C 15:0 (1.0\%), C 17:0 (1.7\%), $\mathrm{C}_{18: 0}(1.0 \%), \mathrm{C}_{17: 1 \omega 8 \mathrm{c}}(2.6)$, and $\mathrm{C}_{20: 1 \omega 9 \mathrm{c}}$ (1.3\%) [37]. A similar fatty acid composition was reported by Kulichevskaya et al. [25], who also reported the presence of long chain, saturated al- 
cohols and diols. The dominant lipopolysaccharide hydroxy fatty acid of strain Mü 290 ${ }^{\mathrm{T}}$ are $\mathrm{C}_{3-\mathrm{OH}}$ 14:0 (74.1\%), $\mathrm{C}_{3-\mathrm{OH}}$ 20:0 (22.5\%), and $\mathrm{C}_{3-\mathrm{OH}}$ 18:0 (3.4\%) [37]. The sole respiratory lipoquinone is MK-6, a feature of all members of the aerobic members of the family Planctomycetaceae examined to date [38]. Like all members of Sittig and Schlesner's group 3 Planctomycetes the type strain produced phosphatidylmonomethylethanolamine, phospha- tidyldimethyl-ethanolamine, a glycolipid and smaller amounts of phosphatidylglycerol, phosphatidylcholine and bisphosphatidylglycerol [38].

A survey on the cellular polyamine pattern of members of the order Planctomycetales revealed $P$. limnophilus strain Mü $290^{\mathrm{T}}$ to contain a large amount of putrescine and a relatively small amount of spermidine [8].

Table 1. Classification and general features of $P$. limnnphilus Mü $290^{\top}$ according to the MIGS recommendations [13]

\begin{tabular}{|c|c|c|c|}
\hline MIGS ID & Property & Term & Evidence code \\
\hline & \multirow{8}{*}{ Current classification } & Domain Bacteria & TAS [14] \\
\hline & & Phylum Planctomycetes & TAS [15] \\
\hline & & Class Planctomycetacia & TAS [15] \\
\hline & & Order Planctomycetales & TAS [16] \\
\hline & & Family Planctomycetaceae & TAS [16] \\
\hline & & Genus Planctomyces & TAS $[3-5,17]$ \\
\hline & & Species Planctomyces limnophilus & TAS [1] \\
\hline & & Type strain Mü 290 & TAS [1] \\
\hline & Gram stain & negative & TAS [1] \\
\hline & Cell shape & $\begin{array}{l}\text { spherical to ovoid mother cells with stalks } \\
\text { composed of twisted fibrils, sessile mothercells } \\
\text { produces motile daughter cells }\end{array}$ & TAS [1] \\
\hline & Motility & monotrichously and polarly flagellated & TAS [1] \\
\hline & Sporulation & non-sporulating & TAS [1] \\
\hline & Temperature range & $17-39^{\circ} \mathrm{C}$ & TAS [1] \\
\hline & Optimum temperature & $30-32^{\circ} \mathrm{C}$ & TAS [1] \\
\hline & Salinity & $<1 \% \mathrm{NaCl}$ & TAS [1] \\
\hline \multirow[t]{3}{*}{ MIGS-22 } & Oxygen requirement & aerobic & TAS [1] \\
\hline & Carbon source & $\begin{array}{l}\text { D-glucose, D-galactose, maltose, cellobiose, } \\
\mathrm{N} \text {-acetyl glucosamine }\end{array}$ & TAS [1] \\
\hline & Energy source & carbohydrates & TAS [1] \\
\hline MIGS-6 & Habitat & lakes and pools & TAS [1] \\
\hline MIGS-15 & Biotic relationship & free-living & TAS [1] \\
\hline \multirow[t]{3}{*}{ MIGS-14 } & Pathogenicity & not reported & NAS \\
\hline & Biosafety level & 1 & TAS [18] \\
\hline & Isolation & surface water of a lake & TAS [1] \\
\hline MIGS-4 & Geographic location & Lake Plußsee, Holstein, Germany & TAS $[1,19]$ \\
\hline MIGS-5 & Sample collection time & 1977 or before & TAS $[1,19]$ \\
\hline $\begin{array}{l}\text { MIGS-4.1 } \\
\text { MIGS-4.2 }\end{array}$ & $\begin{array}{l}\text { Latitude } \\
\text { Longitude }\end{array}$ & $\begin{array}{l}54.182 \\
10.445\end{array}$ & NAS \\
\hline MIGS-4.3 & Depth & surface waters & NAS \\
\hline MIGS-4.4 & Altitude & about sea level & NAS \\
\hline
\end{tabular}

Evidence codes - IDA: Inferred from Direct Assay (first time in publication); TAS: Traceable Author Statement (i.e., a direct report exists in the literature); NAS: Non-traceable Author Statement (i.e., not directly observed for the living, isolated sample, but based on a generally accepted property for the species, or anecdotal evidence). These evidence codes are from of the Gene Ontology project [20]. If the evidence code is IDA, then the property was directly observed by one of the authors or an expert mentioned in the acknowledgements 


\section{Genome sequencing and annotation Genome project history}

This organism was selected for sequencing on the basis of its phylogenetic position [39], and is part of the Genomic Encyclopedia of Bacteria and Archaea project [40]. The genome project is deposited in the Genome OnLine Database [32] and the complete genome sequence is deposited in GenBank. Sequencing, finishing and annotation were performed by the DOE Joint Genome Institute (JGI). A summary of the project information is shown in Table 2.

Table 2. Genome sequencing project information

\begin{tabular}{|c|c|c|}
\hline MIGS ID & Property & Term \\
\hline MIGS-31 & Finishing quality & Finished \\
\hline MIGS-28 & Libraries used & $\begin{array}{l}\text { Two genomic libraries: } \\
\text { one Sanger } 8 \text { kb pMCL200 library, one } 454 \\
\text { pyrosequence standard library }\end{array}$ \\
\hline MIGS-29 & Sequencing platforms & ABI3730, 454 GS FLX, Illumina GAii \\
\hline MIGS-31.2 & Sequencing coverage & $4.8 \times$ Sanger; $19.1 \times$ pyrosequence \\
\hline MIGS-30 & Assemblers & Newbler version 1.1.02.15, PGA \\
\hline \multirow[t]{6}{*}{ MIGS-32 } & Gene calling method & Prodigal 1.4, GenePRIMP \\
\hline & INSDC ID & $\begin{array}{l}\text { CP001744 chromosome } \\
\text { CP001745 plasmid }\end{array}$ \\
\hline & Genbank Date of Release & May 17, 2010 \\
\hline & GOLD ID & Gc01328 \\
\hline & NCBI project ID & 29411 \\
\hline & Database: IMG-GEBA & 2501533208 \\
\hline \multirow[t]{2}{*}{ MIGS-13 } & Source material identifier & DSM 3776 \\
\hline & Project relevance & Tree of Life, GEBA \\
\hline
\end{tabular}

\section{Growth conditions and DNA isolation}

P. limnophilus Mü 2907, DSM 3776, was grown in DSMZ medium 621 (PYGV medium) [41] at $28^{\circ} \mathrm{C}$. DNA was isolated from $0.5-1 \mathrm{~g}$ of cell paste using Qiagen Genomic 500 DNA Kit (Qiagen, Hilden, Germany) following the standard protocol as recommended by the manufacturer, with doubled incubation time ( 1 hour) for cell lysis.

\section{Genome sequencing and assembly}

The genome was sequenced using a combination of Sanger and 454 sequencing platforms. All general aspects of library construction and sequencing can be found at the JGI website. Pyrosequencing reads were assembled using the Newbler assembler version 1.1.02.15 (Roche). Large Newbler contigs were broken into 6,078 overlapping fragments of 1,000 bp and entered into assembly as pseudo-reads. The sequences were assigned quality scores based on Newbler consensus q-scores with modifications to account for overlap redundancy and adjust inflated q-scores. A hybrid 454/Sanger assembly was made using the parallel phrap assembler (High Performance Software, LLC). Possible mis-assemblies were corrected and gaps between contigs were closed by editing in Consed, by custom primer walks from sub-clones or PCR products. A total of 18 Sanger finishing reads were produced to close gaps, to resolve repetitive regions, and to raise the quality of the finished sequence. Illumina reads were used to improve the final consensus quality using an inhouse developed tool (the Polisher) [42]. The error rate of the completed genome sequence is less than 1 in 100,000. Together, the combination of the Sanger and 454 sequencing platforms provided $23.9 \times$ coverage of the genome. The final assembly contains 43,393 Sanger reads and 544,012 pyrosequencing reads.

\section{Genome annotation}

Genes were identified using Prodigal [43] as part of the Oak Ridge National Laboratory genome annotation pipeline, followed by a round of manual curation using the IGI GenePRIMP pipeline [44]. The predicted CDSs were translated and used to search the National Center for Biotechnology Information (NCBI) nonredundant database, UniProt, TIGRFam, Pfam, PRIAM, KEGG, COG, and InterPro databases. Additional gene prediction analysis and functional annotation was performed within the Integrated Microbial Genomes - Expert Review (IMG-ER) platform [45]. 


\section{Genome properties}

The genome consists of a 5,460,075 bp long chromosome and a 37,010 bp long plasmid with a total $\mathrm{G}+\mathrm{C}$ content of $53.7 \%$ (Table 3 and Figure 3). Of the 4,370 genes predicted, 4,304 were protein- coding genes, and 66 RNAs; 46 pseudogenes were also identified. The majority of the protein-coding genes (53.9\%) were assigned a putative function while the remaining ones were annotated as hypothetical proteins. The distribution of genes into COGs functional categories is presented in Table 4.

Table 3. Genome Statistics

\begin{tabular}{lll}
\hline Attribute & Value & \% of Total \\
\hline Genome size (bp) & $5,446,085$ & $100.00 \%$ \\
DNA coding region (bp) & $4,619,194$ & $84.60 \%$ \\
DNA G+C content (bp) & $2,931,217$ & $53.68 \%$ \\
Number of replicons & 2 & \\
Extrachromosomal elements & 1 & \\
Total genes & 4,370 & $100.00 \%$ \\
RNA genes & 66 & $1.51 \%$ \\
rRNA operons & 1 & \\
Protein-coding genes & 4,304 & $98.49 \%$ \\
Pseudo genes & 46 & $1.05 \%$ \\
Genes with function prediction & 2,355 & $53.89 \%$ \\
Genes in paralog clusters & 353 & $8.08 \%$ \\
Genes assigned to COGs & 2,463 & $56.36 \%$ \\
Genes assigned Pfam domains & 2,691 & $61.58 \%$ \\
Genes with signal peptides & 1,008 & $23.07 \%$ \\
Genes with transmembrane helices & 1,126 & $25.77 \%$ \\
CRISPR repeats & 1 & \\
\hline
\end{tabular}
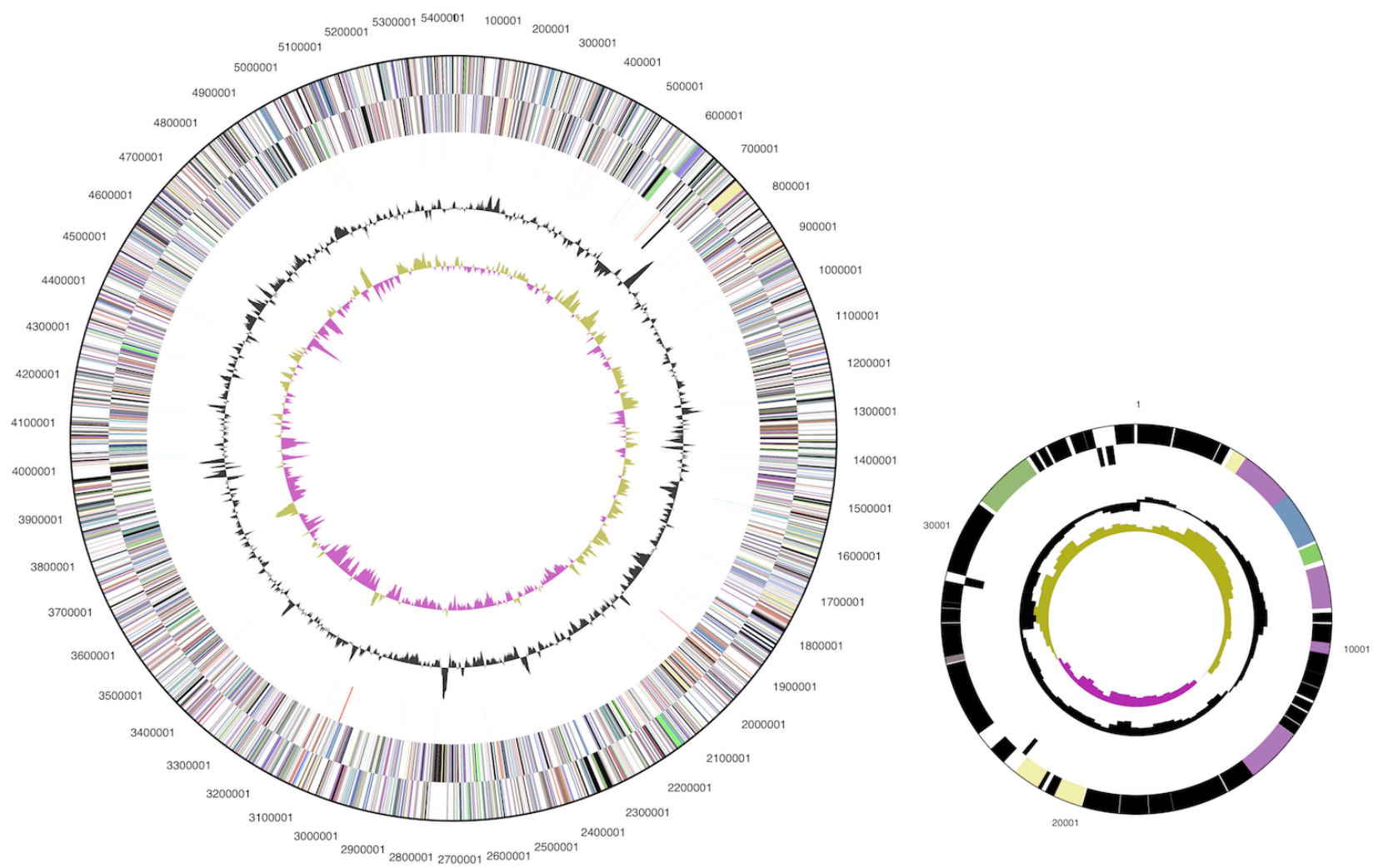

Figure 3. Graphical circular map of the chromosome and the plasmid (not drawn to scale). From outside to the center: Genes on forward strand (color by COG categories), Genes on reverse strand (color by COG categories), RNA genes (tRNAs green, rRNAs red, other RNAs black), GC content, GC skew. 
Table 4. Number of genes associated with the general COG functional categories

\begin{tabular}{crrl}
\hline Code & value & \%age & Description \\
\hline J & 149 & 5.2 & Translation, ribosomal structure and biogenesis \\
A & 0 & 0.0 & RNA processing and modification \\
K & 172 & 6.0 & Transcription \\
L & 141 & 4.9 & Replication, recombination and repair \\
B & 1 & 0.0 & Chromatin structure and dynamics \\
D & 22 & 0.8 & Cell cycle control, cell division, chromosome partitioning \\
Y & 0 & 0.0 & Nuclear structure \\
V & 67 & 2.3 & Defense mechanisms \\
T & 168 & 5.8 & Signal transduction mechanisms \\
M & 166 & 5.8 & Cell wall/membrane/envelope biogenesis \\
N & 150 & 5.2 & Cell motility \\
Z & 0 & 0.0 & Cytoskeleton \\
W & 0 & 0.0 & Extracellular structures \\
U & 178 & 6.2 & Intracellular trafficking, secretion, and vesicular transport \\
O & 124 & 4.3 & Posttranslational modification, protein turnover, chaperones \\
C & 161 & 5.6 & Energy production and conversion \\
G & 154 & 5.4 & Carbohydrate transport and metabolism \\
E & 192 & 6.7 & Amino acid transport and metabolism \\
F & 54 & 1.9 & Nucleotide transport and metabolism \\
H & 127 & 4.4 & Coenzyme transport and metabolism \\
I & 73 & 2.5 & Lipid transport and metabolism \\
P & 148 & 5.1 & Inorganic ion transport and metabolism \\
Q & 54 & 1.9 & Secondary metabolites biosynthesis, transport and catabolism \\
R & 370 & 12.9 & General function prediction only \\
S & 206 & 7.2 & Function unknown \\
- & 1,907 & 43.6 & Not in COGs \\
\hline & & & \\
& &
\end{tabular}

\section{Acknowledgements}

We would like to gratefully acknowledge the help of Helga Pomrenke (DSMZ) for growing cultures of P. limnophilus. This work was performed under the auspices of the US Department of Energy's Office of Science, Biological and Environmental Research Program, and by the University of California, Lawrence Berkeley National Laboratory under contract No. DE-AC02-05CH11231,
Lawrence Livermore National Laboratory under Contract No. DE-AC52-07NA27344, and Los Alamos National Laboratory under contract No. DE-AC0206NA25396, UT-Battelle and Oak Ridge National Laboratory under contract DE-AC05-000R22725, as well as German Research Foundation (DFG) INST 599/1-2 and SI 1352/1-2.

\section{References}

1. Hirsch P, Müller M. Planctomyces limnophilus sp. nov., a stalked and budding bacterium from freshwater. Syst Appl Microbiol 1986; 6:276-280.

2. Euzéby JP. List of bacterial names with standing in nomenclature: A folder available on the Internet. Int J Syst Bacteriol 1997; 47:590-592. PubMed doi:10.1099/00207713-47-2-590

3. Gimesi N. Hydrobiologiai talmanyok (Hydrobiologische Studien). I. Planktomyces bekefii Gim. nov. gen. et sp. Budapest, Kiadja a Magyar Ciszterci. Rend, pp. 1-8. 1924.

4. Skerman VBD, McGowan V, Sneath PHA. Approved Lists of Bacterial Names. Int / Syst Bacte- 
riol 1980; 30:225-420. doi:10.1099/00207713$\underline{30-1-225}$

5. Hirsch P, Skuja HL. 1974. Genus Planctomyces Gimesi 1924, 4., p. 162-163. In RE Buchanan and NE Gibbons (eds), Bergey's Manual of Determinative Bacteriology, $8^{\text {th }}$ edition The Williams and Wilkins Co, Baltimore.

6. Langó Z. Who Has First Observed Planctomyces. Acta Microbiol Immunol Hung 2005; 52:73-84. PubMed doi:10.1556/AMicr.52.2005.1.3

7. Starr MP, Schmidt JM. Planctomyces stranskae (ex Wawrik 1952) sp. nov., nom. rev. and Planctomyces guttaeformis (ex Hortobagyi 1965) sp. nov., nom. rev. Int J Syst Bacteriol 1984; 34:470477. doi:10.1099/00207713-34-4-470

8. Griepenburg U, Ward-Rainey N, Mohamed S, Schlesner H, Marxsen H, Rainey FA, Stackebrandt E, Auling G. Phylogenetic diversity, polyamine pattern and DNA base composition of members of the order Planctomycetales. Int I Syst Bacteriol 1999; 49:689-696. PubMed doi:10.1099/00207713-49-2-689

9. Leary BA, Ward-Rainey N, Hoover TR. Cloning and characterization of Planctomyces limnophilus rpoN: complementation of a Salmonella typhimurium rpoN mutant strain. Gene 1998; 221:151157. PubMed doi:10.1016/S03781119(98)00423-5

10. Ward-Rainey N, Rainey F, Stackebrandt E. The presence of a dnaK (HSP70) multigene family in members of the orders Planctomycetales and Verrucomicrobiales. J Bacteriol 1997; 179:63606366. PubMed

11. Ward-Rainey N, Rainey FA, Wellington EM, Stackebrandt E. Physical map of the genome of Planctomyces limnophilus, a representative of the phylogenetically distinct planctomycete lineage. J Bacteriol 1996; 178:1908-1913. PubMed

12. Butler MK, Fuerst JA. Comparative analysis of ribonuclease P RNA of the planctomycetes. Int I Syst Evol Microbiol 2004; 54:1333-1344. PubMed doi:10.1099/ijs.0.03013-0

13. Field D, Garrity G, Gray T, Morrison N, Selengut J, Sterk P, Tatusova T, Thomson N, Allen MJ, Angiuoli SV, et al. The minimum information about a genome sequence (MIGS) specification. Nat Biotechnol 2008; 26:541-547. PubMed doi:10.1038/nbt1360

14. Woese CR, Kandler O, Wheelis ML. Towards a natural system of organisms: proposal for the domains Archaea, Bacteria, and Eucarya. Proc Natl
Acad Sci USA 1990; 87:4576-4579. PubMed doi:10.1073/pnas.87.12.4576

15. Garrity GM, Holt JG. 2001. The road map to the Manual, 2 edition, vol. 1. p 119-166. Springer, New York.

16. Schlesner H, Stackebrandt E. Assignment of the genera Planctomyces and Pirella to a new family Planctomycetaceae fam. nov. and description of the order Planctomycetales ord. nov. Syst Appl Microbiol 1986; 8:174-176.

17. Judicial Commission of the International Committee on Systematics of Prokaryotes. The nomenclatural types of the orders Acholeplasmatales, Halanaerobiales, Halobacteriales, Methanobacteriales, Methanococcales, Methanomicrobiales, Planctomycetales, Prochlorales, Sulfolobales, Thermococcales, Thermoproteales and Verrucomicrobiales are the genera Acholeplasma, Halanaerobium, Halobacterium, Methanobacterium, Methanococcus, Methanomicrobium, Planctomyces, Prochloron, Sulfolobus, Thermococcus, Thermoproteus and Verrucomicrobium, respectively. Opinion 79. Int J Syst Evol Microbiol 2005; 55:517-518. PubMed doi:10.1099/ijs.0.63548-0

18. Classification of bacteria and archaea in risk groups. http://www.baua.de TRBA 466.

19. Hirsch P, Müller M, Schlesner H. 1977. New aquatic budding and prosthecate bacteria and their taxonomic position. Proceed. Sympos. Aquatic Microbiology, Lancaster U.K. Soc Appl Bacteriol Sympos Ser No 6. Academic Press, London.

20. Ashburner M, Ball CA, Blake JA, Botstein D, Butler $\mathrm{H}$, Cherry JM, Davis AP, Dolinski K, Dwight SS, Eppig JT, et al. Gene Ontology: tool for the unification of biology. Nat Genet 2000; 25:25-29. $\underline{\text { PubMed doi:10.1038/75556 }}$

21. Bauld J, Staley JT. Planctomyces maris sp. nov., nom. rev. Int J Syst Bacteriol 1980; 30:657. doi:10.1099/00207713-30-4-657

22. Lindsay MR, Webb RI, Strous M, Jetten MS, Butler MK, Forde RJ, Fuerst JA. Cell compartmentalisation in planctomycetes: novel types of structural organisation for the bacterial cell. Arch Microbiol 2001; 175:413-429. PubMed doi:10.1007/s002030100280

23. Schlesner H. Planctomyces brasiliensis sp. nov., a halotolerant bacterium from a salt pit. Syst Appl Microbiol 1989; 12:159-161.

24. Chun J, Lee JH, Jung Y, Kim M, Kim S, Kim BK, Lim YW. EzTaxon: a web-based tool for the identification of prokaryotes based on $16 \mathrm{~S}$ ribosomal 
RNA gene sequences. Int / Syst Evol Microbiol

2007; 57:2259-2261. PubMed

doi:10.1099/ijs.0.64915-0

25. Kulichevskaya IS, Ivanova AO, Belova SE, Baulina OI, Bodelier PLE, Rijpstra WIC, Sinninghe Damste JS, Zavarzin GA, Dedysh SN. Schlesneria paludicola gen. nov., sp. nov., the first acidophilic member of the order Planctomycetales, from Sphagnum-dominated boreal wetlands. Int J Syst Evol Microbiol 2007; 57:2680-2687. PubMed doi:10.1099/ijs.0.65157-0

26. Rattray RM, Perumbakkam S, Smith F, Craig AM. Microbiomic comparison of the intestine of the earthworm Eisenia fetida fed ergovaline. Curr Microbiol 2010; 60:229-235. PubMed doi:10.1007/s00284-009-9530-8

27. Castresana J. Selection of conserved blocks from multiple alignments for their use in phylogenetic analysis. Mol Biol Evol 2000; 17:540-552. PubMed

28. Lee C, Grasso C, Sharlow MF. Multiple sequence alignment using partial order graphs. BioinformatiCs 2002; 18:452-464. PubMed doi:10.1093/bioinformatics/18.3.452

29. Stamatakis A, Hoover P, Rougemont J. A Rapid Bootstrap Algorithm for the RAxML Web Servers. Syst Biol 2008; 57:758-771. PubMed doi:10.1080/10635150802429642

30. Yarza P, Richter M, Peplies J, Euzeby J, Amann R, Schleifer KH, Ludwig W, Glöckner FO, RossellóMóra R. The All-Species Living Tree project: A $16 \mathrm{~S}$ rRNA-based phylogenetic tree of all sequenced type strains. Syst Appl Microbiol 2008; 31:241-250. PubMed doi:10.1016/j.syapm.2008.07.001

31. Pattengale ND, Alipour M, Bininda-Emonds OR, Moret BM, Stamatakis A. How many bootstrap replicates are necessary? Lect Notes Comput Sci 2009; 5541:184-200. doi:10.1007/978-3-642$\underline{02008-7 \quad 13}$

32. Liolios K, Chen IM, Mavromatis K, Tavernarakis N, Hugenholtz P, Markowitz VM, Kyrpides NC. The Genomes On Line Database (GOLD) in 2009: status of genomic and metagenomic projects and their associated metadata. Nucleic Acids Res 2010; 38:D346-D354. PubMed doi:10.1093/nar/gkp848

33. Clum A, Tindall BJ, Sikorski J, Ivanova N, Mavromatis K, Lucas S, Glavina Del Rio T, Nolan M, Chen $\mathrm{F}$, Tice $\mathrm{H}$, et al. Complete genome sequence of Pirellula staleyi type strain (ATCC $\left.27377^{\top}\right)$. Stand Genomic Sci 2009; 1:308-316. doi:10.4056/sigs.51657

34. Starr MP, Short KA, Schmidt JM. Exclusion of the filamentous and rosette-forming bacterium "Planctomyces gracilis" Hortobagyi 1965 from the Blastocaulis-Planctomyces group. Int I Syst Bacteriol 1984; 34:465-469. doi:10.1099/00207713-34-4$\underline{465}$

35. König E, Schlesner H, Hirsch P. Cell wall studies on budding bacteria of the Planctomyces/Pasteuria group and on a Prosthecomicrobium sp. Arch Microbiol 1984; 138:200-205. doi:10.1007/BF00402120

36. Liesack W, König H, Schlesner H, Hirsch P. Chemical composition of the peptidoglycan-free cell envelopes of budding bacteria of the Pirella/Planctomyces group. Arch Microbiol 1986; 145:361-366. doi:10.1007/BF00470872

37. Kerger BD, Mancuso CA, Nichols PD, White DC, Langworthy T, Sittig M, Schlesner H, Hirsch P. The budding bacteria, Pirellula and Planctomyces, with atypical $16 \mathrm{~S}$ rRNA and absence of peptidoglycan, show eubacterial phospholipids and uniquely high proportions of long chain betahydroxy fatty acids in the lipopolysaccharide lipid A. Arch Microbiol 1988; 149:255-260. doi:10.1007/BF00422014

38. Sittig M, Schlesner $\mathrm{H}$. Chemotaxonomic investigation of various prosthecate and/or budding bacteria. Syst App/ Microbiol 1993; 16:92-103.

39. Klenk HP, Göker M. En route to a genome-based classification of Archaea and Bacteria? Syst Appl Microbiol 2010; 33:175-182. PubMed doi:10.1016/j.syapm.2010.03.003

40. Wu D, Hugenholtz P, Mavromatis K, Pukall R, Dalin E, Ivanova NN, Kunin V, Goodwin L, Wu $\mathrm{M}$, Tindall BJ, et al. A phylogeny-driven genomic encyclopaedia of Bacteria and Archaea. Nature 2009; 462:1056-1060. PubMed $\underline{\text { doi:10.1038/nature08656 }}$

41. List of growth media used at DSMZ: http://www.dsmz.de/microorganisms/media list.p hp.

42. Lapidus A, LaButti K, Foster B, Lowry S, Trong S, Goltsman E. POLISHER: An effective tool for using ultra short reads in microbial genome assembly and finishing. AGBT, Marco Island, FL, 2008.

43. Hyatt D, Chen GL, Locascio PF, Land ML, Larimer FW, Hauser LJ. Prodigal Prokaryotic Dynamic Programming Genefinding Algorithm. BMC 
Bioinformatics 2010; 11:119. PubMed doi:10.1186/1471-2105-11-119

44. Pati A, Ivanova N, Mikhailova N, Ovchinikova G, Hooper SD, Lykidis A, Kyrpides NC. GenePRIMP: A gene prediction improvement pipeline for microbial genomes. Nat Methods 2010; 7:455-457. PubMed doi:10.1038/nmeth.1457
45. Markowitz VM, Ivanova NN, Chen IMA, Chu K, Kyrpides NC. IMG ER: a system for microbial genome annotation expert review and curation. Bioinformatics 2009; 25:2271-2278. PubMed doi:10.1093/bioinformatics/btp393 